\title{
Estudo da fertilidade de um Latossolo Vermelho-Amarelo húmico sob cultivo de café arábica por meio de geoestatística ${ }^{1}$
}

\author{
Samuel de Assis Silva², Julião Soares de Souza Lima ${ }^{3}$, Gustavo Soares de Souza ${ }^{4}$
}

\begin{abstract}
Este trabalho teve por objetivo avaliar a fertlidade de um Latossolo Vermelho-Amarelo húmico, sob cultivo de café arábica, por meio de técnicas de geoestatística uni e multivariada. O estudo foi realizado em uma área cultivada com Coffea arabica L. variedade catuaí, em uma malha, totalizando 50 pontos. A amostragem de solo foi realizada na profundidade de $0-0,2 \mathrm{~m}$, para determinar os atributos $\mathrm{P}, \mathrm{K}, \mathrm{Ca}, \mathrm{Mg}$, argila, areia e silte. Os valores encontrados foram analisados por meio da estatística descritiva e exploratória, seguida de análise geoestatística. Os atributos foram interpolados por krigagem ordinária e cokrigagem. O solo apresentou, de modo geral, baixa fertilidade. A utilização da areia na estimativa dos valores de $\mathrm{K}$ acarretou a superestimativa dos valores deste nutriente, na região mais alta da área, e subestimativa, nas regiões mais baixas. A estimativa de Mg em função do silte possibilitou obter um mapa representativo da sua distribuição com menor erro.
\end{abstract}

Palavras-chave: Coffea arabica L., cokrigagem, fertilidade do solo, variabilidade espacial.

\section{RESUMO}

\section{Geostatistics to determine the fertility of an oxisol under arabic coffee plantation}

The objective of this work was to evaluate the fertlity of a humic Red-Yellow Latosol under cultivation of Arabic coffee, using uni and multivariate geoestatistics. The study was carried out in an area cultivated with Coffea arabica L. var. Catuaí, in a grid area totaling 50 points. Soil samples were collected at the depth of $0-0.2 \mathrm{~m}$ and the attributes $\mathrm{P}$, $\mathrm{K}, \mathrm{Ca}, \mathrm{Mg}$, clay, sand and silt were evaluated. Data were analyzed using descriptive and exploratory statistics, and then by geoestatistics techniques. The attributes were interpolated by ordinary kriging and cokriging. The soil had, overall, low fertility. The use of sand to estimate K values led to overestimation of this nutrient in the region's highest area and underestimation in the lowest areas. Estimation of $\mathrm{Mg}$ as a function of silt provided a more representative map of its distribution with less error.

Key words: Coffea arabica L., cokriging, spatial variability, soil fertility

\footnotetext{
Recebido para publicação em junho de 2008 e aprovado em setembro de 2009

${ }^{1}$ Extraído da Dissertação de Mestrado do primeiro autor.

2Engenheiro-Agrônomo, Doutorando. Departamento de Engenharia Agrícola, Universidade Federal de Viçosa, Av. Peter Henry Rolfs, s/n, 36570-000, Viçosa, MG, Brasil. samuelassis@hotmail.com

${ }^{3}$ Engenheiro-Agrícola, Doutor. Departamento de Engenharia Rural, Alto Universitário, s/n, 29500-000 Alegre, ES, Brasil. limajss@yahoo.com.br

${ }^{4}$ Engenheiro-Agrônomo, Doutorando. Faculdade de Engenharia Agrícola, Universidade Federal de Campinas, Av. Cândido Rondon, Barão Geraldo, 13083-875, Campinas, SP, Brasil. gsdsouza@hotmail.com
} 


\section{INTRODUÇÃO}

A crescente demanda de nutrientes por cultivares de café, cada vez mais produtivos, assim como a expansão de lavouras para solos de baixa fertilidade, vem exigindo melhor compreensão da dinâmica dos nutrientes na cultura, para que sejam evitados problemas de deficiência nutricional, que muito prejudicam a eficiência dos programas de adubação, reduzindo consideravelmente a produção (Reis Jr. \& Martinez, 2002).

Os diversos atributos químicos do solo (macro e micronutrientes) apresentam valores bastante diferenciados, ao longo das diversas formas de relevo, por causa das alterações provocadas pelo manejo agrícola, e, ainda, pelos processos erosivos. Silva \& Chaves (2001) comentam que os atributos químicos apresentam maior variação que os físicos em uma área cultivada e, por esse fato, o uso de amostragem aleatória, utilizando a média para caracterizar determinado atributo no solo, seria insuficiente para caracterizar toda uma classe de solo.

O conhecimento da variação de atributos químicos é importante para o levantamento e manejo do solo, o planejamento de esquemas de amostragem e o gerenciamento de práticas agrícolas. Antes de buscar qualquer relação desses elementos com a cultura, é importante avaliar a extensão e a intensidade da dependência espacial dessa variação, isoladamente ou em conjunto com outros parâmetros (Gandah et al., 2000).

A variabilidade espacial dos solos é resultado de processos pedogenéticos e pode ser demonstrada por resultados dos levantamentos e análises, sendo que as propriedades químicas e físicas têm interligações específicas entre si, de tal forma que essas interações influenciam diretamente o crescimento e o desenvolvimento das culturas (Souza et al., 2004). Dessa forma, a avaliação conjunta da variabilidade espacial e das propriedades químicas e físicas do solo é uma importante ferramenta na determinação de estratégias de manejo do solo, que procuram aumentar a produtividade agrícola.

Este trabalho teve por objetivo avaliar a fertilidade de um Latossolo Vermelho- Amarelo húmico, sob cultivo de café arábica, utilizando técnicas de geoestatística uni e multivariada.

\section{MATERIAL E MÉTODOS}

O estudo foi realizado na Zona da Mata de Minas Gerais, no município de Reduto, em uma área cultivada com Coffea arabica L. variedade catuaí, no espaçamento de 2,0 x $0,60 \mathrm{~m}$, localizada a $20^{\circ} 45^{\prime} 45,4^{\prime}$ ' de latitude S e $41^{\circ}$ $32^{\prime}$ 9,75' de longitude W. A área apresenta diferença de nível acentuada com $30^{\circ}$ de declividade e altitude superior a $800 \mathrm{~m}$. O solo é um Latossolo Vermelho-Amarelo húmico, comhorizonte "A" bastante espesso e rico em matéria orgânica, conforme classificação apresentada pela Embrapa (1999).

Para a realização da análise química e física dos atributos do solo, foram coletadas amostras na profundidade de $0-0,2 \mathrm{~m}$ e na projeção das copas de três plantas, totalizando 50 pontos georreferenciados (Figura 1). As amostras simples de solo foram homogeneizadas para formar uma composta, passando o conjunto de três plantas a ser denominado de célula de amostragem.

A fertilidade do solo foi analisada com base nos atributos fósforo $(\mathrm{P})$, potássio $(\mathrm{K})$, cálcio $(\mathrm{Ca})$ e magnésio (Mg), seguindo o método apresentado pela Embrapa (1997). A granulometria foi analisada por meio das frações de argila, silte e areia total. Os valores encontrados foram analisados por meio das medidas de posição e dispersão, na análise da estatística descritiva e exploratória, e, também na análise de correlação entre os atributos químicos e físicos. Para verificar a presença de pontos candidatos a valores discrepantes "outliers", foram analisados os quartis superiores e inferiores e a normalidade foi testada pelo teste Kolmogorov-Smirnov $(\mathrm{p}<0,05)$, utilizando-se o software Statistica 6.0 (Statsoft, 2001).

A geoestatística foi utilizada para verificar a existência de, e, neste caso, quantificar o grau de, dependência espacial, a partir do ajuste de funções teóricas aos modelos de semivariogramas (Equação 1) e semivariogramas cruzados (Equação 2) experimentais, com base na pressuposição de estacionaridade da hipótese intrínseca (Vieira et al., 1983) e conforme equação:

$$
\begin{aligned}
& \gamma^{*}(h)=\frac{1}{2 N(h)} \sum_{i=1}^{N(h)}\left[z\left(x_{i}\right)-z\left(x_{i}+h\right)\right]^{2} \\
& \gamma_{12}^{*}(h)=\frac{1}{2 N(h)} \sum_{i=1}^{N(h)}\left[z_{1}\left(x_{1 i}\right)-z_{1}\left(x_{i 1}+h\right)\right]\left[z_{2}\left(x_{2 i}\right)-\right. \\
& \left.-z_{2}\left(x_{2 i}+h\right)\right]
\end{aligned}
$$

em que: N(h) é o número de pares experimentais de observações $\mathrm{Z}\left(\mathrm{x}_{\mathrm{i}}\right), \mathrm{Z}\left(\mathrm{x}_{\mathrm{i}}+\mathrm{h}\right)$, separados por um vetor $\mathrm{h}$ e $\mathrm{Z} 1$ e $\mathrm{Z} 2$ são variáveis correlacionadas espacialmente.

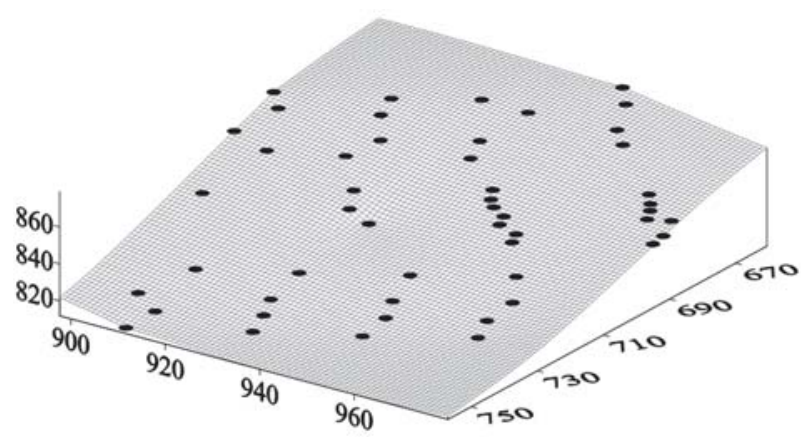

Figura 1. Modelo digital de elevação (MDE) da área com a distribuição dos pontos amostrais. 
Os modelos teóricos para ajuste foram: esférico, exponencial, gaussiano, linear sem patamar e efeito pepita puro. A escolha do modelo seguiu os critérios adotados pelo software GS+ (Robertson, 1998), que utiliza a menor soma do quadrado dos resíduos (SQR) e o maior coeficiente de determinação $\left(\mathrm{R}^{2}\right)$.

No ajuste dos modelos teóricos aos semivariogramas experimentais, determinaram-se os coeficientes efeito pepita $\left(\mathrm{C}_{0}\right)$, patamar $\left(\mathrm{C}_{0}+\mathrm{C}_{1}\right)$, variância estrutural $\left(\mathrm{C}_{1}\right)$ e alcance (a) pelo software GS+ (Robertson, 1998). Para análise do índice de dependência espacial (IDE), foram utilizados a relação $\mathrm{C}_{1} /\left(\mathrm{C}_{0}+\mathrm{C}_{1}\right)$ e os intervalos propostos por Zimback (2001),que considera a dependência espacial fraca (IDE < 25\%); moderada (25\% < IDE < 75\%) e forte (IDE > 75\%).

Para estimar valores dos atributos químicos e físicos, em locais não amostrados, e confeccionar os mapas de isolinhas, utilizou-se a krigagem ordinária. Esse interpolador geoestatístico utiliza um estimador linear não viciado com mínima variância, leva em consideração a estrutura de variabilidade espacial encontrada para o atributo e é definido pela seguinte equação:

$z^{*}\left(x_{i}, x_{i}+h\right)=\sum_{i=1}^{n} \lambda i Z\left(x_{i}, x_{i}+h\right)$

sujeito a: $\sum_{i=1}^{n} \lambda i=1$

em que $\mathrm{Z}^{*}\left(\mathrm{x}_{\mathrm{i}}, \mathrm{x}_{\mathrm{i}}+\mathrm{h}\right)$ é o estimador para um ponto $\left(\mathrm{x}_{\mathrm{i}}, \mathrm{x}_{\mathrm{i}}+\mathrm{h}\right)$ da região e $\lambda i$ são os pesos usados na estimativa.

Para espacializar os atributos químicos em função das frações granulométricas, utilizou-se a extensão multivariada da krigagem, conhecida como cokrigagem. Esta estimativa pode ser mais precisa do que a krigagem de uma variável simples, quando o semivariograma cruzado mostrar dependência entre as duas variáveis (Vieira, 2000).

Na cokrigagem (Vieira, 2000), para estimar valores, $\mathrm{Z}_{2}{ }^{*}$, para qualquer local, o valor estimado $\mathrm{X}_{0}$ deve ser uma combinação linear de ambos, $\mathrm{Z}_{1}$ e $\mathrm{Z}_{2}$, ou seja:

$z_{2} *\left(x_{0}\right)=\sum_{i=1}^{N 1} \lambda_{1 i} z\left(x_{1 i}\right)+\sum_{j=1}^{N 2} \lambda_{2 j} z_{2}\left(x_{2 j}\right)$

em que $\mathrm{N}_{1}$ e $\mathrm{N}_{2}$ são os números de vizinhos de $\mathrm{Z}_{1}$ e $\mathrm{Z}_{2}$, respectivamente, e $l_{1}$ e $l_{2}$ são os pesos associados a cada valor de $\mathrm{Z}_{1}$ e $\mathrm{Z}_{2}$. Tomando $\mathrm{z}_{1}\left(\mathrm{x}_{1 \mathrm{i}}\right)$ e $\mathrm{z}_{2}\left(\mathrm{x}_{2 \mathrm{j}}\right)$ como sendo uma realização das funções aleatórias $Z_{1}\left(X_{1 \mathrm{i}}\right)$ e $Z_{2}\left(X_{2 j}\right)$, respectivamente, e assumindo estacionaridade de ordem 2 , o estimador pode ser reescrito como:

$Z_{2} *\left(x_{0}\right)=\sum_{i=1}^{N 1} \lambda_{1 i} Z\left(X_{1 i}\right)+\sum_{j=1}^{N 2} \lambda_{2 j} Z_{2}\left(X_{2 j}\right)$ expressando que a estimativa da variável Z2 deverá ser uma combinação linear de ambos, $Z_{1}$ e $Z_{2}$ com os pesos $\lambda_{1}$ e $\lambda_{2}$ distribuídos de acordo com a dependência espacial de cada uma das variáveis entre si e a correlação cruzada entre elas.

As interpolações foram realizadas no software GS + (Robertson, 1998) sendo os mapas confeccionados no software Surfer (Golden Software, 2002).

\section{RESULTADOS E DISCUSSÃO}

Por meio da análise exploratória, foi possível identificar a presença de valores discrepantes “outliers” nos dados dos atributos químicos e físicos do solo, bem como sua influência sobre as medidas de posição e dispersão, o que proporcionou sua eliminação.

Os resultados obtidos pela análise estatística descritiva encontram-se na Tabela 1, onde se observa que, para todos os atributos, os valores das medidas de tendência central (média e mediana) ficaram bem próximos, indicando distribuição simétrica, confirmada pelos valores de simetria próximos de zero. De acordo com Isaaks \& Srivastava (1989), o coeficiente de assimetria é mais sensível a valores extremos do que a média, mediana e o desvio-padrão, uma vez que um único valor pode influenciar fortemente o coeficiente de assimetria, pois os desvios entre cada valor e a média são elevados à terceira potência.

Todos os atributos apresentaram distribuição normal pelo teste de Kolmogorov- Smirnov a 5\% de probabilidade. Paz-Gonzalez et al. (2001) afirmam que, quando satisfeita a normalidade dos dados, a estimativa de valores em locais não medidos, utilizando-se o método da krigagem na interpolação, tem sua eficiência aumentada, apresentando melhores resultados em relação a outros métodos.

Analisando a variabilidade, por meio do coeficiente de variação (CV), constata-se que, com excessão da areia e da argila, que apresentaram baixa variação, os demais atributos apresentaram variação média de acordo com a classificação proposta por Warrick \& Nielsen (1980), de baixa para $\mathrm{CV}<12 \%$; média de $12 \%<\mathrm{CV}<60 \%$ e alta para $\mathrm{CV}>60 \%$. A maior variação foi observada para o $\mathrm{P}$, justificada por sua maior amplitude total. Esse alto CV, também observado por Silva et al. (2008) que trabalharam também com café, ocorre, provavelmente, em razão dos efeitos residuais de adubações anteriores, haja vista que este elemento apresenta baixa mobilidade e, geralmente, é adicionado na linha, na superficie do solo.

De um modo geral, analisando os atributos químicos que foram investigados nesta pesquisa, pode-se dizer que o solo apresenta baixa fertilidade, sendo os valores médios dos atributos químicos classificados, de acordo com Ribeiro et al. (1999), para o Estado de Minas Gerais, em muito baixo para P, baixo para Ca e Mg e bom para o K. 
Tabela 1 - Estatística descritiva e distribuição de frequência dos atributos químicos e físicos do solo em área cultivada com café

\begin{tabular}{|c|c|c|c|c|c|c|c|c|c|}
\hline \multirow{2}{*}{ Atributos } & \multicolumn{9}{|c|}{ Estatística } \\
\hline & Média & Mediana & Mínimo & Máximo & $\mathrm{CV}(\%)$ & $\mathbf{s}$ & $\mathrm{C}_{\mathrm{s}}$ & $C_{k}$ & p-valor \\
\hline $\mathbf{P}$ & 3,64 & 3,40 & 0,90 & 8,20 & 51,10 & 1,86 & 0,49 & $-0,07$ & 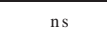 \\
\hline $\mathbf{K}$ & 87,83 & 86,50 & 24,00 & 162,00 & 40,73 & 35,77 & 0,26 & $-0,57$ & ns \\
\hline $\mathrm{Ca}$ & 1,17 & 1,09 & 0,30 & 2,23 & 38,15 & 0,45 & 0,52 & $-0,17$ & ns \\
\hline Mg & 0,40 & 0,37 & 0,09 & 0,82 & 42,90 & 0,17 & 0,46 & $-0,22$ & ns \\
\hline Areia total & 332,35 & 335,75 & 284,96 & 378,97 & 6,94 & 23,06 & $-0,32$ & $-0,07$ & ns \\
\hline Silte & 69,21 & 69,57 & 20,78 & 124,04 & 41,78 & 28,92 & 0,20 & $-0,99$ & ns \\
\hline Argila & 464,72 & 463,86 & 381,07 & 555,97 & 8,42 & 39,12 & $-0,05$ & $-0,06$ & ns \\
\hline
\end{tabular}

P e K em mg dm${ }^{-3}$; Ca e $\mathrm{Mg}$ em cmol $_{c} \mathrm{dm}^{-3}$; Areia, Silte e Argila em $\mathrm{g} \mathrm{kg}^{-1}$; CV (\%) - coeficiente de variação; s - desvio-padrão; $\mathrm{C}_{\mathrm{s}}-$ coeficiente de assimetria; $C_{k}$ - coeficiente de curtose; ns: distribuição normal pelo teste Kolmogorov-Smirnov.

Esse nível de fertilidade representa um fator limitante ao desenvolvimento da cultura, inviabilizando bons resultados de produtividade, se não ocorrer a reposição desses elementos de acordo com a exigência da cultura.

Na Tabela 2, verifica-se a correlação linear entre os teores de P, K, Ca e Mg no solo e as frações granulométricas argila, silte e areia, as quais serão utilizadas como co-variáveis para estimar os atributos químicos. A correlação linear é uma exigência da cokrigagem, logo, para serem utilizadas como covariáveis, é necessário que as frações granulométricas sejam correlacionadas com os atributos químicos em estudo.

A correlação linear foi significativa $(\mathrm{p}<0,05)$ somente entre $\mathrm{K}$ e areia total e entre $\mathrm{Mg}$ e silte, indicando plausibilidade na utilização de tais frações granulométricas como auxiliares na determinação da distribuição espacial do K e Mg, respectivamente, por meio da cokrigagem. Como os demais atributos químicos não apresentaram correlação com nenhuma das possíveis covariáveis, não se justifica a utilização da cokrigagem na sua estimativa.

A correlação negativa de K com a areia total mostra que a sua disponibilidade é maior em locais onde os valores de areia são menores. Esse comportamento inverso entre a disponibilidade de $\mathrm{K}$ e a concentração de areia total no solo relaciona-se a processos de lixiviação. Em solos com quantidade considerável de areia, observam-se perdas acentuadas nesse nutriente, por causa da lixiviação. Mello et al. (2004) afirmam que, em solos intemperizados como os Latossolos, que muitas vezes são pobres em materiais de origem, os teores totais mais baixos de K estão relacionados com a fração areia. Castilhos (1999) afirma que a areia é a fração que libera a menor quantidade de potássio, o que pode ser explicado pela sua mineralogia, mais pobre em minerais potássicos, constituída predominantemente pelo mineral quartzo.

A relação Mg-Silte (correlação positiva) segue comportamento inverso à da discutida anteriormente, sendo os valores de disponibilidade de Mg maiores em locais de maiores teores de silte. De acordo com Corrêa et al. (2003), a fração silte pode contribuir para o aumento da concentração de cálcio, magnésio e potássio, na solução do solo,
Tabela 2 - Coeficiente de correlação de Pearson entre os atributos químicos e físicos do solo em área cultivada com café

\begin{tabular}{|c|c|c|c|c|}
\hline \multirow{2}{*}{ Atributos } & \multicolumn{4}{|c|}{ FísicosAtributos Químicos } \\
\hline & $\mathbf{P}$ & $\mathbf{K}$ & $\mathrm{Ca}$ & Mg \\
\hline Areia total & $0,20^{\mathrm{ns}}$ & $-0,45^{*}$ & $-0,18^{\mathrm{ns}}$ & $-0,26^{\mathrm{ns}}$ \\
\hline Silte & $0,13^{\text {ns }}$ & 0,29 ns & $0,28^{\mathrm{ns}}$ & $0,39^{*}$ \\
\hline Argila & $-0,27$ ns & $-0,07$ ns & $-0,15^{\mathrm{ns}}$ & $-0,22$ ns \\
\hline
\end{tabular}

e essa contribuição é maior com a presença do sódio trocável. Esses mesmos autores salientam que essa contribuição é mais representativa em solos ricos em feldspatos-K, plagioclásios e calcita.

Os resultados da análise geoestatística (Figura 2) indicam que os atributos areia total, silte e argila apresentam dependência espacial, ajustando-se, com base nos critérios pré-estabelecidos, o modelo esférico para alcance de 8, 30 a $12 \mathrm{~m}$, respectivamente. O silte apresentou maior continuidade espacial que areia total e argila, observada pelo seu maior alcance de dependência espacial.

Nos mapas da Figura 3, interpolados por krigagem ordinária, observa-se a distribuição das frações na área em estudo. Podem-se ver, pelos mapas, uma grande amplitude nos atributos físicos estudados e a influência visual da declividade sobre sua distribuição.

Os maiores valores de areia são encontrados na porção inferior direita da área, sendo que a maior parte da área apresenta valores entre 290 e $350 \mathrm{~g} \mathrm{~kg}^{-1}$. A argila tem distribuição mais aleatória, com maior proporção da área com valores entre 430 e $480 \mathrm{~g} \mathrm{~kg}^{-1}$, enquanto, para o silte, a maior proporção da área apresenta concentrações entre 50 e $100 \mathrm{~g} \mathrm{~kg}^{-1}$.

Os semivariogramas experimentais, utilizados para avaliar a dependência espacial dos atributos químicos, estão apresentados na Figura 3. Todos os atributos apresentaram dependência espacial, ajustando-se, com base nos critério pré-estabelecidos, o modelo esférico para o $\mathrm{P}$ com alcance de $12 \mathrm{~m}$ e o modelo gaussiano para K, Ca e Mg com alcance de 66, 60 a 89 m, respectivamente. 
Considerando-se o alcance, a distribuição espacial dos atributos químicos não é aleatória, uma vez que todos apresentaram valores moderados ou fortes para o índice de dependência espacial (IDE). O IDE para o K, Ca e Mg apresenta-se moderado, com valores entre $25 \%$ e $75 \%$, enquanto o P apresenta IDE elevado (> 75\%), conforme classificação proposta por Zimback (2001) (Figura 4). Valores seme-

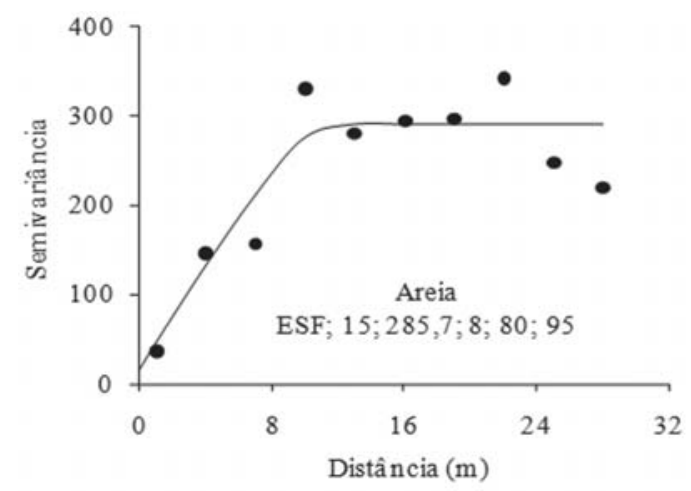

lhantes foram observados por Silva et al. (2008), trabalhando com café arábica em duas safras agrícolas.

A estimativa de valores dos atributos químicos para locais não amostrados é apresentada na (Figura 5). A escala dos mapas é baseada nos valores de referência para a cultura do café no Estado de Minas Gerais, segundo Ribeiro et al. (1999).
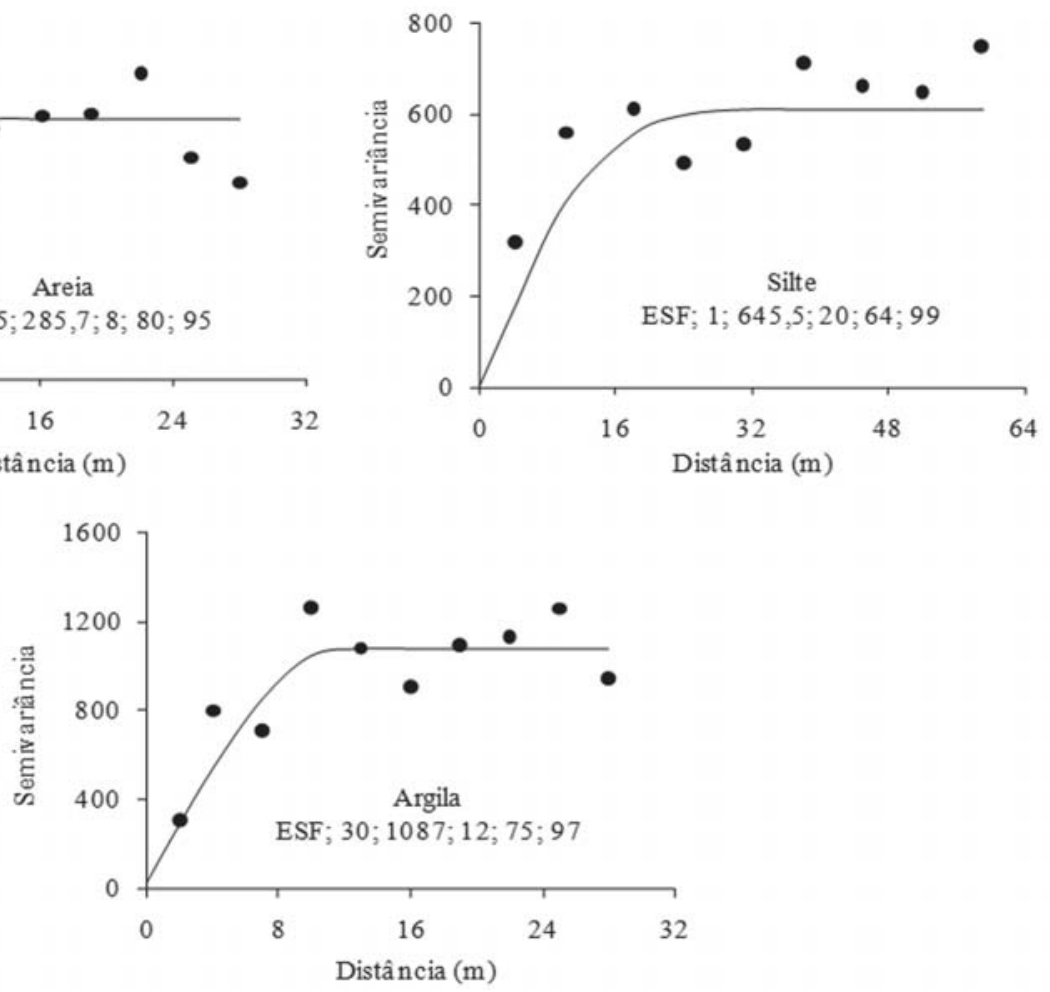

Figura 2 - Modelos e parâmetros dos semivariogramas $\left(\mathrm{C}_{0} ; \mathrm{C}_{0}+\mathrm{C} ; \mathrm{A}_{0} ; \mathrm{R}^{2}\right.$; IDE) das frações granulométricas (areia, silte e argila).
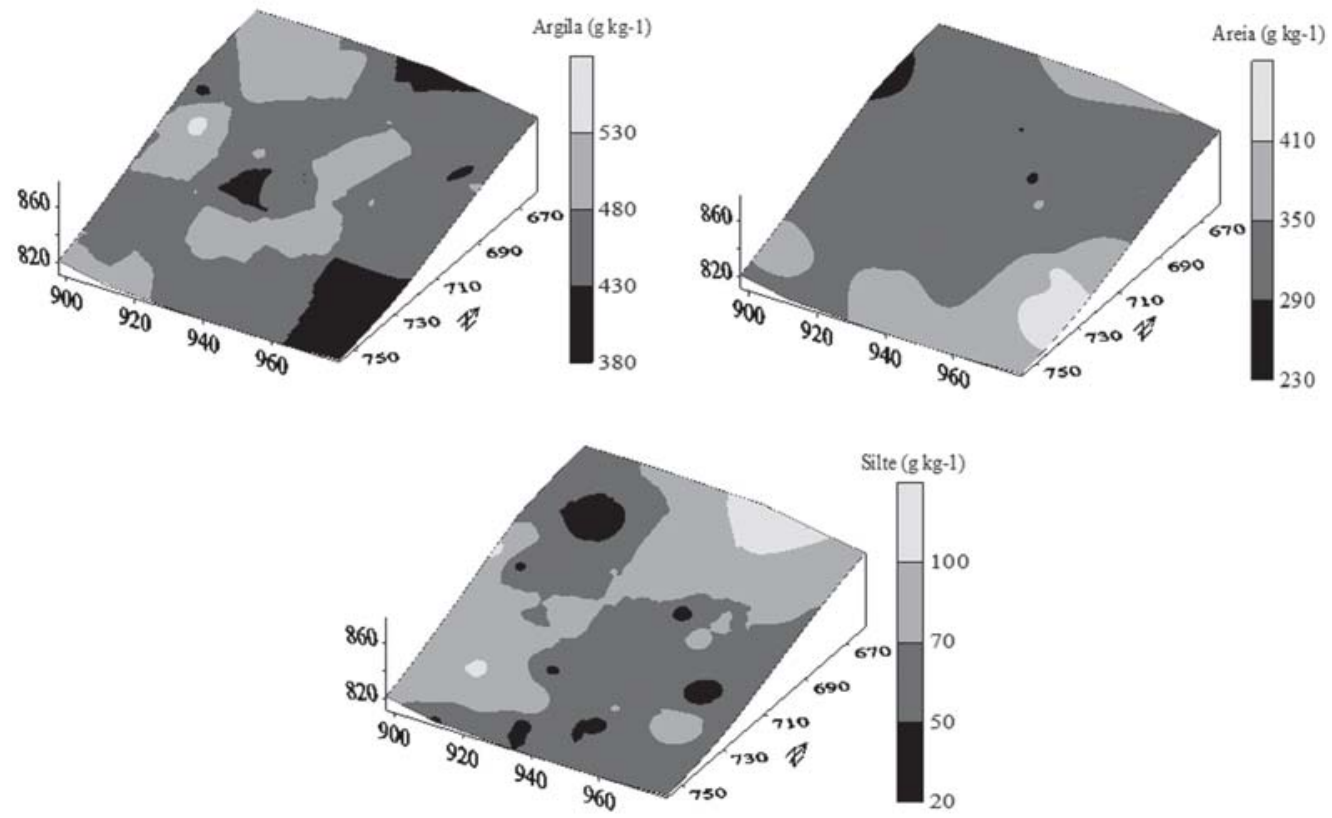

Figura 3 - Distribuição espacial das frações granulométricas (argila, areia e silte) em área cultivada com café. 
Conforme discutido anteriormente, os níveis dos nutrientes, com excessão do K, foram “muito baixos” e “baixos”. A maior proporção da área apresenta valores de $\mathrm{P}$ muito baixos $(<4)$, com uma pequena porção da região superior, onde esses níveis são classificados como
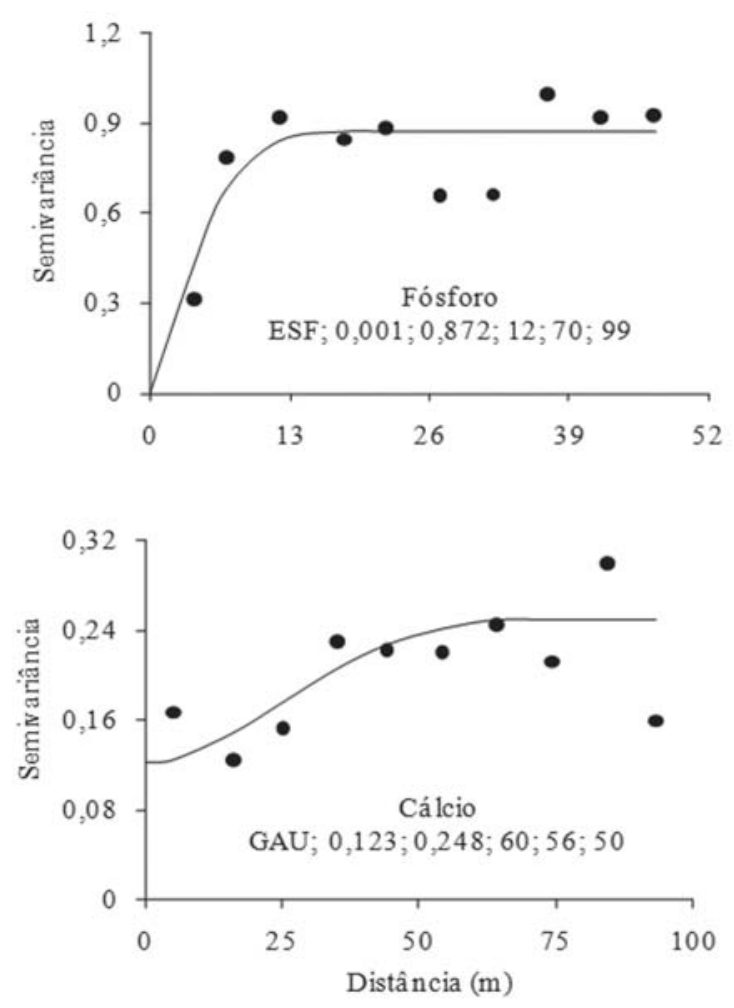

baixos $(4-8)$. O potássio tem níveis satisfatórios ao desenvolvimento da cultura do café, sendo que a parte mais baixa da área apresenta os menores valores, os quais situam-se na classe média (40 - 70). Os níveis de Ca e os de Mg na área dividem-se entre médios $(0,4-1,2)$ para
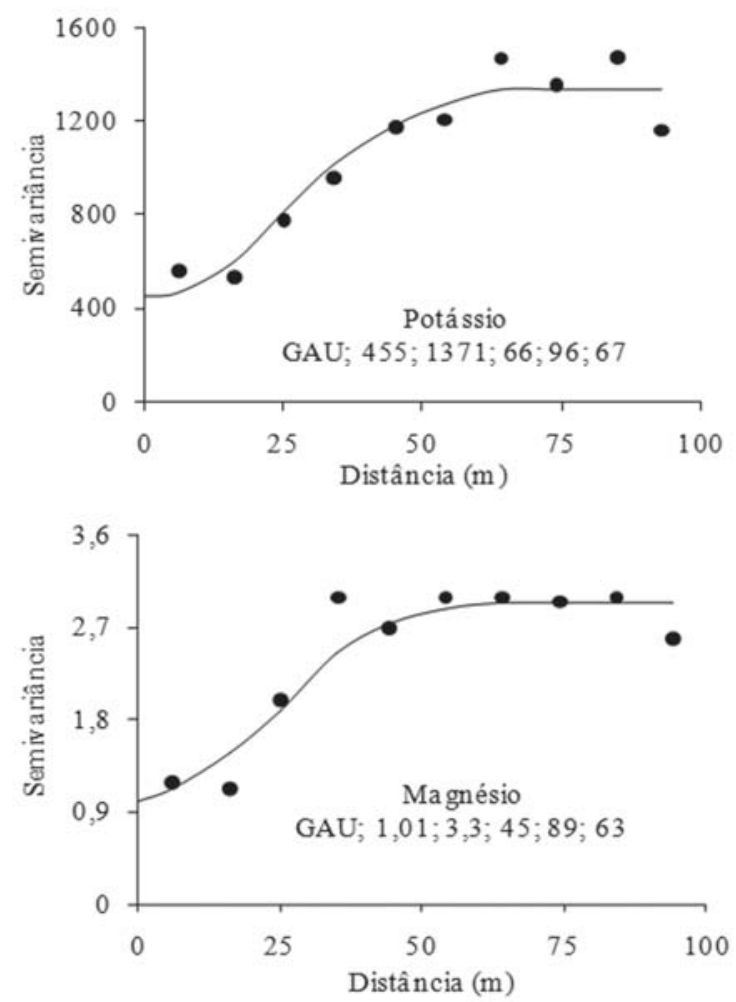

Figura 4 - Modelos e parâmetros dos semivariogramas $\left(\mathrm{C}_{0} ; \mathrm{C}_{0}+\mathrm{C} ; \mathrm{A}_{0} ; \mathrm{R}^{2} ;\right.$ IDE) dos atributos fósforo, potássio, cálcio e magnésio em área cultivada com café.
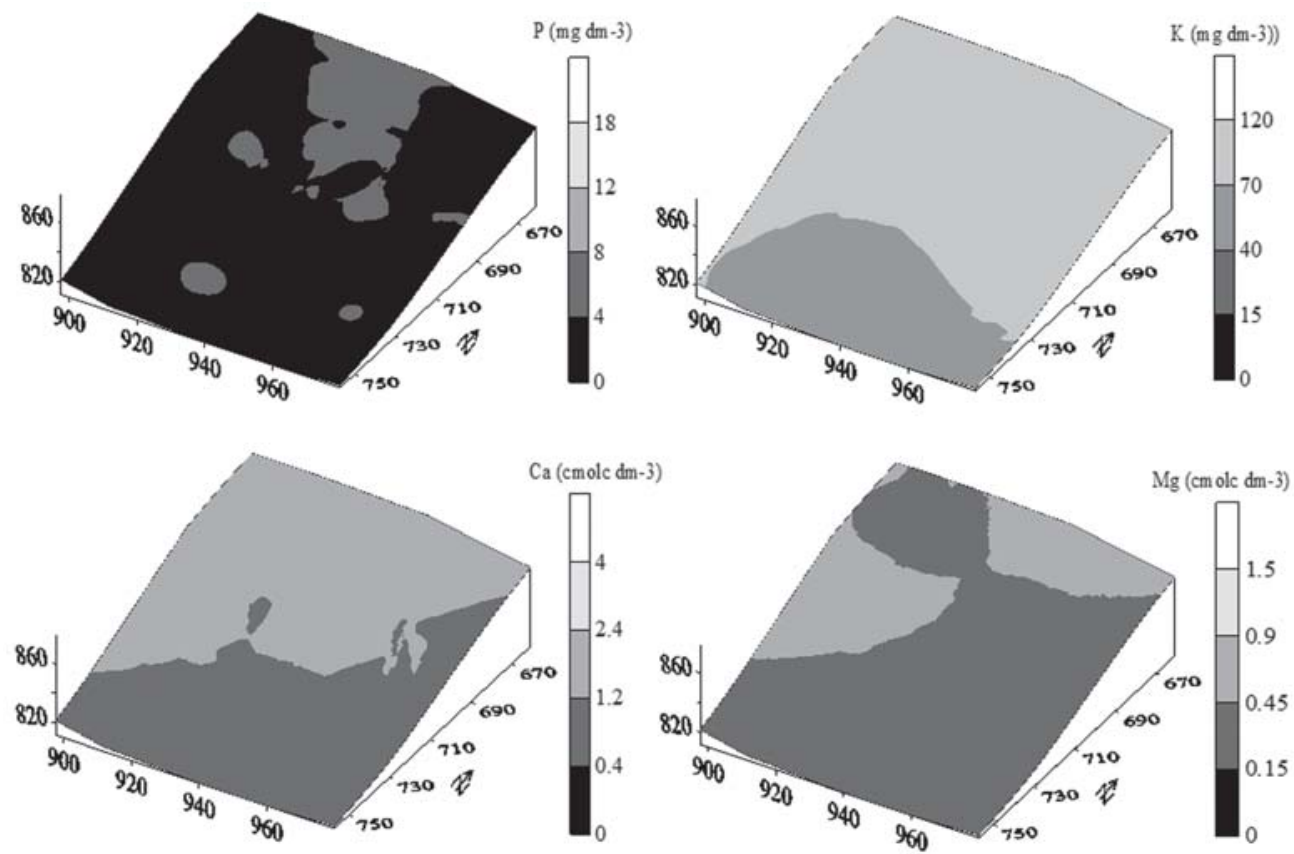

Figura 5 - Distribuição espacial do fósforo, potássio, cálcio e magnésio em área cultivada com café. 
Ca e $(0,15-0,45)$ para Mg e baixos $(1,2-2,4)$ para Ca e $(0,45-0,9)$ para $\mathrm{Mg}$. Em todos os casos, a declividade foi decisiva na disponibilidade dos nutrientes, sendo esta menor em locais mais baixos da área. Esse comportamento, no entanto, não foi tão evidenciando para o P, uma vez que quase $100 \%$ da área apresenta valores muito baixos.

Para as situações que apresentaram correlação espacial significativa entre duas variáveis, fez-se a estimativa utilizando-se o semivariograma cruzado, conforme apresentado na Figura 6.

Ajustou-se a ambos o modelo esférico, com alcance de 8 a 44 m, para K-areia total e Mg-silte, respectivamente. Mg-silte apresenta maior continuidade espacial que KAreia, por causa do seu maior alcance. Esse valor de alcance elevado é resultado de ter ele sido observado para o silte e para o $\mathrm{Mg}$, analisados individualmente. O valor baixo de alcance para potássio-areia é resultado do alcance reduzido, apresentado pela areia total, quando analisada individualmente.

Os semivariogramas cruzados evidenciam o comportamento inverso, entre níveis de K e teor de areia total do solo, conforme a Figura 6, e o comportamento semelhante, entre Mg e silte, como se observa nos mapas da Figura 7, interpolados por cokrigagem. A escala dos mapas é, também, baseada nos valores de referência para a cultura do café, no Estado de Minas Gerais, segundo Ribeiro et al. (1999), para os elementos K e Mg, utilizando-se, respectivamente, areia e silte como covariáveis.

Quando se utiliza a areia total na estimativa dos valores de K, observa-se que, apesar de manter a maior proporção de área entre os níveis de médio e bom, os valores são superestimados para as região mais alta e subestimado para a mais baixa da área de estudo. Esse fato está relacionado com o menor alcance encontrado para o semivariograma cruzado (menor alcance para areia), proporcionando maior estratificação da área.

Esse comportamento não foi observado para o Mg, quando o silte é utilizado como covariável na sua estimativa. Como os valores de alcance de silte e Mg, individualmente, foram elevados, o semivariograma cruzado entre eles apresentou igualmente alcance superior, fornecendo um mapa mais representativo da realidade.

No entanto, ao comparar os mapas de cada atributo, individualmente, e os mapas resultante da cokrigagem, em relação a sua distribuição em função da declividade, observou-se que estes são coerentes, ou seja, os maiores teores de areia situam-se na parte de baixo, e, os menores, na parte de cima, sendo que, para o K, o comportamento é inverso, enquanto os menores valores de silte localizamse na parte baixa da área e na porção superior estão os maiores valores, assim como para o Mg.
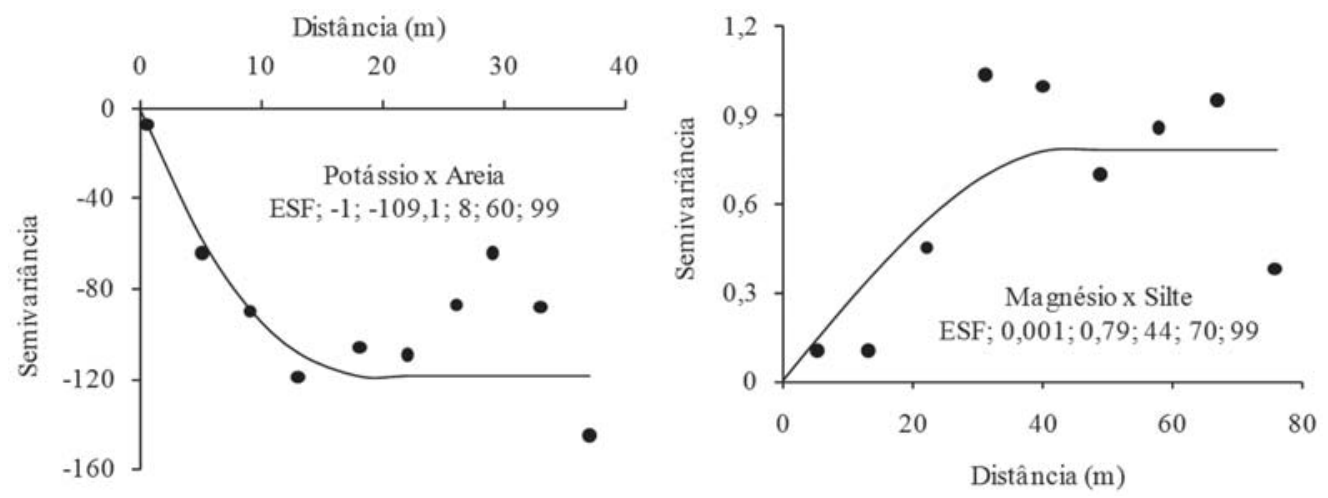

Figura 6 - Modelos e parâmetros dos semivariogramas cruzados $\left(\mathrm{C}_{0} ; \mathrm{C}_{0}+\mathrm{C} ; \mathrm{A}_{0} ; \mathrm{R}^{2}\right.$; IDE) para potássio x areia e magnésio x silte.
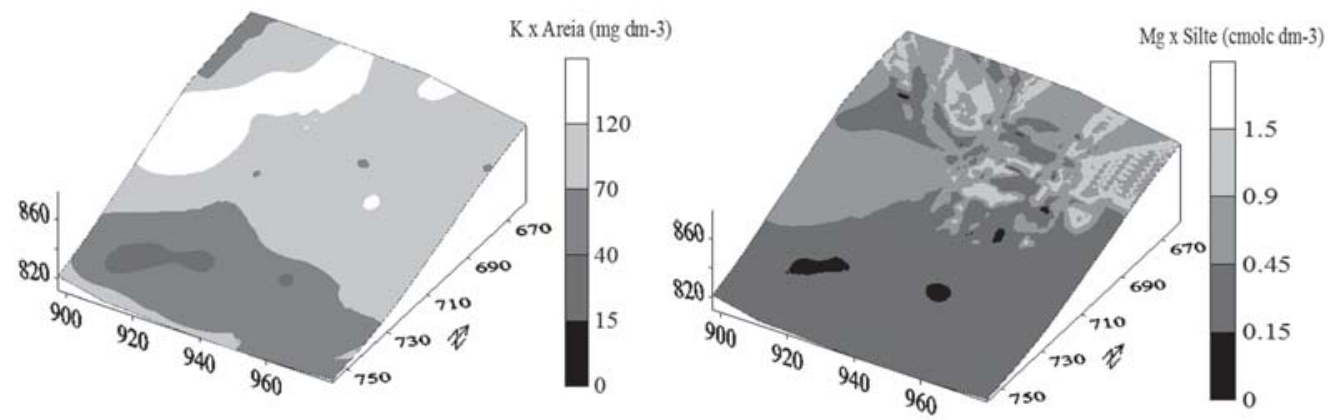

Figura 7 - Distribuição espacial de potássio e magnésio, estimados por cokrigagem. 


\section{CONCLUSÔES}

Todas as variáveis estudadas apresentaram estrutura de dependência espacial, com ausência de aleatoriedade na sua distribuição.

Os métodos geoestatísticos multivariados permitiram eficiência na caracterização química do solo, possibilitando redução do número de análises laboratoriais, para a interpretação do comportamento de distribuição espacial da fertilidade.

Os resultados mostraram que a cokrigagem pôde realizar a estimativa do K e Mg, eficientemente, usandose, como covariáveis, os teores de areia e silte, respectivamente.

\section{AGRADECIMENTOS}

À CAPES pela bolsa de mestrado concedida ao primeiro autor.

\section{REFERÊNCIAS BIBLIOGRÁFICAS}

Castilhos RMV (1999) Suprimento de potássio em solos cultivados com arroz irrigado e sua relação com mineralogia, formas e cinética de liberação. Tese de Doutorado. Faculdade de Agronomia, Universidade Federal do Rio Grande do Sul, Porto Alegre, $175 p$.

Corrêa MM, Ker JC, Mendonça ES, Ruiz HA, Bastos RS (2003) Atributos físicos, químicos e mineralógicos de solos da região das várzeas de Sousa (PB). Revista Brasileira de Ciência do Solo, 27:311-324.

Embrapa (1997) Manual de métodos de análise de solo. $2^{\mathrm{a}}$ ed. Rio de Janeiro, Centro Nacional de Pesquisa de Solos. 212p.

Embrapa (1999) Sistema Brasileiro de Classificação de Solos. $1^{\text {a }}$ ed. Rio de Janeiro, Centro Nacional de Pesquisa de Solos. 412p.

Gandah M, Stein A, Brouwer J, Bouma J (2000) Dynamics of spatial variability of millet growth and yields at three sites in Niger, west Africa and implications for precision agriculture research. Agricultural Systems, 63:123-140.

Golden Software, Surfer version 8.0 (2002) Surface mapping system. In: Golden Software, 1. CD - ROM.

Isaaks EH \& Srivastava RM (1989) An introduction to applied geoestatistics. $1^{\text {a }}$ ed. New York, Oxford University. 561p.

Melo VF, Ribeiro, NA, Maschio PA, Corrêa GF, Lima VC (2004) Mineralogia e formas de potássio e magnésio em diferentes classes de pesos e tamanhos da fração areia de solos do triângulo mineiro. Revista Brasileira de Ciência do Solo, 28:219-231.

Paz-Gonzalez A, Taboada MTC, Vieira SR (2001) Geostatistical analysis of heavy metals in a one-hectare plot under natural vegetation in a serpentine area. Canadian Journal of Soil Science, 81:469-479.

Reis Jr RA \& Martinez HEP (2002) Adição de Zn e absorção, translocação e utilização de Zn e P por cultivares de cafeeiro. Scientia Agricola, 59:537-542.

Ribeiro AC, Guimarães PTG, Alvarez V, Ruiz HV (1999) Recomendações para uso de corretivos e fertilizantes em Minas Gerais - $5^{\mathrm{a}}$ Aproximação. Viçosa, Comissão de Fertilidade do Solo do Estado de Minas Gerais. 359p.
Robertson GP (1998) GS+: Geoestatistics for the environmental sciences - GS ${ }^{+}$User's Guide. Plainwell, Gamma Desing Software. $152 \mathrm{p}$.

Silva PCM \& Chaves LHG (2001) Avaliação e variabilidade espacial de fósforo, potássio e matéria orgânica em alissolos. Revista Brasileira de Engenharia Agrícola e Ambiental, 5:431-436.

Silva FM, Souza ZM, Figueiredo CAP, Vieira LHS \& Oliveira E (2008) Variabilidade espacial de atributos químicos e da produtividade da cultura do café em duas safras agrícolas. Ciência e Agrotecnologia, 32:231-241.

Souza ZM, Marques Júnior J, Pereira GT \& Moreira LF (2004) Variabilidade espacial do $\mathrm{pH}, \mathrm{Ca}, \mathrm{Mg}$ e V\% do solo em diferentes formas do relevo sob cultivo de cana-de-açúcar. Ciência Rural, 34:1763-1771.

Statsoft (2001) Statistica for windows. Release 7.0 Yulsa, StatSoft, Inc., Não paginado.

Vieira SR (2000) Geoestatística em estudos de variabilidade espacial do solo. In: Novais RF, Alvarez V, Ruiz VH \& Schaefer GR (Eds.) Tópicos em ciência do solo. Viçosa, Sociedade Brasileira de Ciência do Solo. p.1-53.

Vieira SR, Hatfield JL, Nielsen DR \& Biggar JW (1983) Geostatistical theory and application to variability of some agronomical properties. Hilgardia, 51:1-75.

Warrick AW \& Nielsen DR (1980) Spatial variability of soil physical properties in the field. In: Hillel D (Ed) Applications of soil physics. New York, Academic Press. p.319-344.

Zimback CRL (2001) Análise espacial de atributos químicos de solos para fins de mapeamento da fertilidade do solo. Tese de Livre-Docência. Faculdade de Ciências Agronômicas, Universidade Estadual Paulista, Botucatu, 114p. 